\section{HELPING REDUCE OPERATOR FATIGUE}

Quality Endodontic Distributors Ltd are the UK distributors of the Obtura Max heated gutta percha system, proven to enhance endodontic success.

The Obtura Max heated gutta percha system rapidly fills and obturates even the most difficult root canals more completely, in less time, and with less patient discomfort than any other method.

The Obtura system has been an integral part of the armamentarium of successful endodontists for over 20 years. It delivers controlled and predictable results, ensuring the most effective and efficient 'backfilling' technique possible.
With a choice of different size needles, condensable thermosoftened gutta percha can be used to 'backfill' any root canal system without leaving voids.

The sleek modern design of the Obtura Max unit includes five pre-set programmes, soft touch controls and easy clean surfaces. The lightweight, ergonomically designed handpiece helps reduce operator fatigue.

For further information telephone 01733 404999, email sales@qedendo.

co.uk, or visit www.qedendo.co.uk.

\section{FREE POSTERS AND LEAFLETS}

Techceram Ltd are offering dental practices free IPS e.max ZirCAD posters and patient leaflets so that they can promote the unique benefits of IPS e.max ZirCAD restorations to their patients.

IPS e.max ZirCAD all-ceramic restorations are the ideal alternative to precious metal based restorations. Available in white and four shaded options, IPS e.max ZirCAD is the high performance all-ceramic with a $900 \mathrm{MPa}$ flexural strength and $6 \mathrm{MPa} \mathrm{m}^{0.5}$ fracture toughness. It combines excellent biocompatibility with low heat conductivity and is recommended for anterior bridges of up to six units, including four adjacent pontics, and up to six unit posterior bridges with two adjacent pontics. It is also recommended for anterior cantilever bridges.

In association with all the members of their All-Ceramic Excellence (ACE) group of user laboratories, Techceram offer a complete choice of all-ceramic restorations including: lava zirconia based substructures for single and multiple unit restorations; IPS e.max ZirCAD zirconia based substructures for single and multiple unit restorations; IPS e.max Press and CAD, glass ceramic precision fitting inlay, veneer and crown substructures/ restorations; and In-Ceram CAD Alumina and Spinell substructures for PJC alternative single unit restorations.

For further information contact Techceram Ltd on 01274416664 or visit www.techceram.com.

\section{A GLOBAL DENTAL TOWN}

Dentaltown is the world's largest online community for dental professionals, offering message boards with more than 150,000 members discussing the hottest topics in dentistry, online continuing education, classified ads, monthly polls to highlight current trends in dentistry, and more. You can also subscribe to Dentaltown Magazine for articles and profiles you want to read on topics you actually face in your day-to-day practice. Online membership and magazine subscription are both free. Visit www.dentaltown.com to register. 